\title{
Delayed diagnosis of radiation - associated cutaneous angiosarcoma
}

\section{Nina Korsaga/Somé1,2, Nayi Zongo ${ }^{3}$, Thibault Kervarrec ${ }^{4}$, Aurélie Sallot ${ }^{5}$, Alexandre Penaud ${ }^{6}$, Gonzague de Pinieux ${ }^{4,7}$, Laurent Machet ${ }^{1,7}$}

\author{
${ }^{1}$ Department of Dermatology, CHRU, Tours, France, ${ }^{2}$ Faculty of Health Science of Ouaga 1 Pr Joseph Ki-Zerbo University, \\ Burkina Faso, Burkina Faso, ${ }^{3}$ General and Digestive Surgery, Yalgado Ouédraogo University Hospital, Ouagadougou, \\ Burkina Faso, ${ }^{4}$ Department of Pathology CHRU, Tours, France, ${ }^{5}$ Department of Plastic surgery, CHRU, Tours, France, \\ ${ }^{6}$ Pôle de Santé Léonard de Vinci, Plastic Surgeon, Chambray les Tours, France, ${ }^{7}$ Université François-Rabelais, Tours, France
}

Corresponding author: Dr. Nina Korsaga/Somé, E-mail: nessine2000@yahoo.fr

\begin{abstract}
Angiosarcoma is most frequently occurring in patients treated for a previous cancer with radiation therapy. Our aim was to measure the time between the first signs found by the patient and the first biopsy, and the time before the final diagnosis of radiation-associated angiosarcoma (RAAS) and to analyse the reasons for delayed diagnosis. Four patients met the inclusion criteria. Three had cutaneous RAAS and one had suprapubic cutaneous RAAS after treatment for cancer. The intervals between the first cutaneous sign recorded by the patient and the diagnosis of RAAS were 9 to 37 months. The initial diagnosis by the non-specialist pathologist was a benign vascular lesion. Review of the initial biopsy was consistent with RAAS in 3 cases and with AVL in 1 case. Clinicians should alert pathogists when a vascular lesion is larger than $5 \mathrm{~mm}$ in the context of irradiated skin. Histology review by an expert should be recommended.
\end{abstract}

Key words: Angiosarcoma; Radiation; Pathology; Diagnosis; Atypical vascular lesion; Chemotherapy

\section{INTRODUCTION}

Angiosarcoma (AS) is a rare malignant tumour that develops from endothelial cells. In Europe, the annual incidence of AS is approximately 0.31 cases per 100.000 people [1].

Primary lymphoedema is known to be a contributory factor in the occurrence of cutaneous AS (StewartTreeves syndrome) [2]. Conservative treatment of breast cancer combining lumpectomy, radiotherapy and sentinel lymph node dissection, or more generally combined radio-surgery treatment of non-breast cancer, are also known risk factors for secondary lymphedema [3] and for the development of radiationassociated angiosarcoma (RAAS) [4]. It is difficult from both clinical and histology points of view to distinguish benign vascular lesions from atypical vascular lesions (AVL) and true AS of the skin [5-7].
We report four consecutive cases of cutaneous RAAS occurring in patients who had previously been treated with radiation therapy for cancer. Our aim was to measure the time between the first signs found by the patient and the first biopsy, and the time before the final diagnosis of RAAS and to analyse the reasons for delayed diagnosis.

\section{CASE REPORT}

This is a retrospective series of patients with cutaneous RAAS treated 1 January 2008 and 31 December 2014. The inclusion criteria comprised the development of RAAS located initially in the radiotherapy field that had appeared more than six months after radiotherapy and confirmed by a pathologist with expertise in sarcoma.

We gathered the following data: date of diagnosis of the first cancer, modalities of treatment for the first

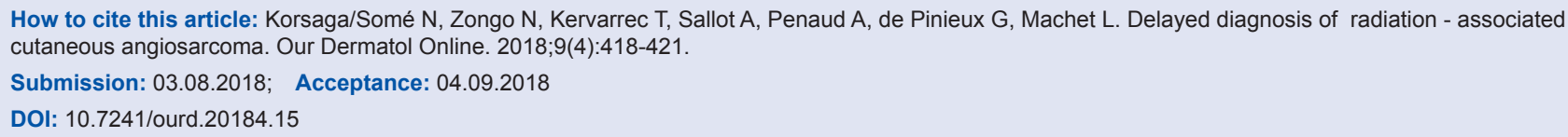


cancer and radiation dose, date of first clinical signs that alerted the patient to the appearance of vascular lesions that led to the diagnosis of RAAS, date of the first biopsy, and date of definitive diagnosis of RAAS. The existence of primary lymphoedema, or secondary lymphoedema induced by treatment for the primary cancer, the treatment modalities and response to treatment, and the date of death were also gathered. Histology slides were stained with a panel of autoantibodies including CD31, CD34, D2-40, Myc and Ki67.

Four patients met the inclusion criteria (Tables I and II). Three had cutaneous RAAS after treatment for breast cancer, and one had suprapubic cutaneous RAAS after treatment for uterine cancer (Fig.1). The interval between treatment of the primary cancer and the occurrence of RAAS ranged between 36 months and 72 months. The intervals between the first cutaneous sign recorded by the patient and the diagnosis of RAAS were 9 to 37 months. The pathogy and clinical diagnoses of AS were unambiguous in all 4 cases at the time of diagnosis (Figs. 1 and 2). First biospy from each patient was reviewed retrospectively by experts in dermatopathology in our centre. In 3 cases, the diagnosis of RAAS was made. In the remaining case, the diagnosis of atypical vascular lesion was made on the biopsy but the diagnosis of RAAS was established after total surgical removal. Initial treatment was wide surgery in two cases. Chemotherapy was offered to the other two patients who were deemed inoperable. They died 7 and 10 months after diagnosis of AS.

Prior to the study, patient gave written consent to the examination and biopsy after having been informed about the procedure.

\section{DISCUSSION}

In this series, the interval between the first clinical signs and diagnosis was longer than 1 year in two of four cases. In addition, at least two biopsies, and a second opinion

Table I: Patients characteristics

\begin{tabular}{|c|c|c|c|c|}
\hline Patient & 1 & 2 & 3 & 4 \\
\hline Age at diagnosis of AS (years) & 84 & 85 & 78 & 53 \\
\hline Sex & $\mathrm{F}$ & $\mathrm{F}$ & $\mathrm{F}$ & $\mathrm{F}$ \\
\hline Location & Suprapubic & Breast & Breast & Breast \\
\hline Primary cancer & Uterus & Breast & Breast & Breast \\
\hline Pre-existing lymphedema & None & None & None & None \\
\hline Acquired lympoedema & Yes & Yes & Yes & Yes \\
\hline Radical lymph node surgery & Yes & Yes & Yes & Yes \\
\hline Radiation dose (Gray) & 60 & 30 & 59.5 & 60 \\
\hline Chemotherapy for primary cancer & None & None & None & Paclitaxel and herceptine \\
\hline $\begin{array}{l}\text { Interval between radiation therapy } \\
\text { and diagnosis of AS (months) }\end{array}$ & 72 & 70 & 36 & 45 \\
\hline $\begin{array}{l}\text { Interval between first clinical signs } \\
\text { and diagnosis of AS (months) }\end{array}$ & 15 & 10 & 9 & 37 \\
\hline $\begin{array}{l}\text { Interval between first biopsy and diagnosis of } \\
\text { AS (months) }\end{array}$ & 0 & 6 & 25 & 35 \\
\hline Number of biopsies & 1 & 3 & 2 & 2 \\
\hline Histology review of the first biopsy & AS & AS & AVL & AS \\
\hline Treatment for AS & $\begin{array}{l}\text { Chemotherapy } \\
\text { Bevacizumab } \\
3 \text { months (PD) } \\
\text { Paclitaxel } 2 \text { months (PD) }\end{array}$ & $\begin{array}{l}\text { Chemotherapy } \\
\text { Paclitaxel } 3 \text { months (PD) } \\
\text { Doxorubicine } \\
3 \text { months (PR) }\end{array}$ & $\begin{array}{l}\text { Mastectomy } \\
\text { Paclitaxel } 6 \text { months (CR) } \\
\text { Pazopanib (CR) }\end{array}$ & $\begin{array}{l}\text { Mastectomy } \\
\text { Paclitaxel } 3 \text { months } \\
\text { (PD) } \\
\text { Pazopanib (NE) }\end{array}$ \\
\hline Overall survival since diagnosis of AS (months) & 7 & 10 & 44 & 12 \\
\hline Alive & No & No & Yes & Yes \\
\hline
\end{tabular}

$\mathrm{PD}=$ progressive disease; $\mathrm{PR}=$ partial response; $\mathrm{CR}=$ complete response; $\mathrm{NE}=$ not evaluable

Table II: Main pathology findings

\begin{tabular}{lcccc} 
Patient & $\mathbf{1}$ & $\mathbf{2}$ & $\mathbf{3}$ & $\mathbf{4}$ \\
\hline Histology of RAAS & Conventional angiosarcoma & Conventional angiosarcoma & AVL followed by conventional angiosarcoma & Epithelioid angiosarcoma \\
Grading & 3 & 2 & 3 & 3 \\
CD31 & + & + & +++ & + \\
CD34 & + & + & + & + \\
D2-40 & + & + & + & + \\
Myc & few cells stained & + & AVL $<1 \%$ AS $>20 \%$ & + \\
Ki 67 & $20 \%$ & $25 \%$ & & $+60 \%$ \\
\hline
\end{tabular}




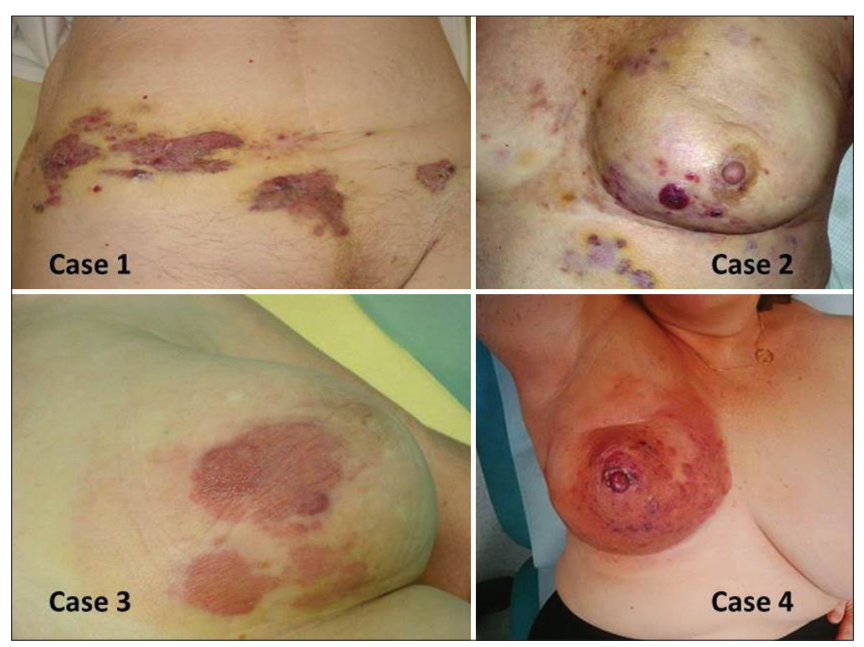

Figure 1: Clinical lesions. Case 1: infiltrated, papular lesions, purplish extended, seen at the level of the pelvic area, bounded by points of radiation, in a patient of 84 , which occurred 6 years after radiation therapy for cancer of the cervix, in a patient of 84. Case 2: Nodular lesions, with vascular appearance on the left breast, diffused, bursting to the contralateral breast with a painful infiltration of the whole left breast, occurring 7 after radiation therapy for left breast carcinoma in a patient of 85. Case 3: Angiomatous erythematous plaque on the left breast took place 4 years after radiation therapy for infiltrating ductal breast carcinoma on the same treated breast, in a 78-year-woman. Case 4: Lymphedema and breast fibrosis, topped with an Erythematous cutaneous plaque, infiltrated, including lymphangiectasia, extended to the whole right breast, occurred 4 years after radiation therapy for cancer of the right breast, in a patient of 54 .

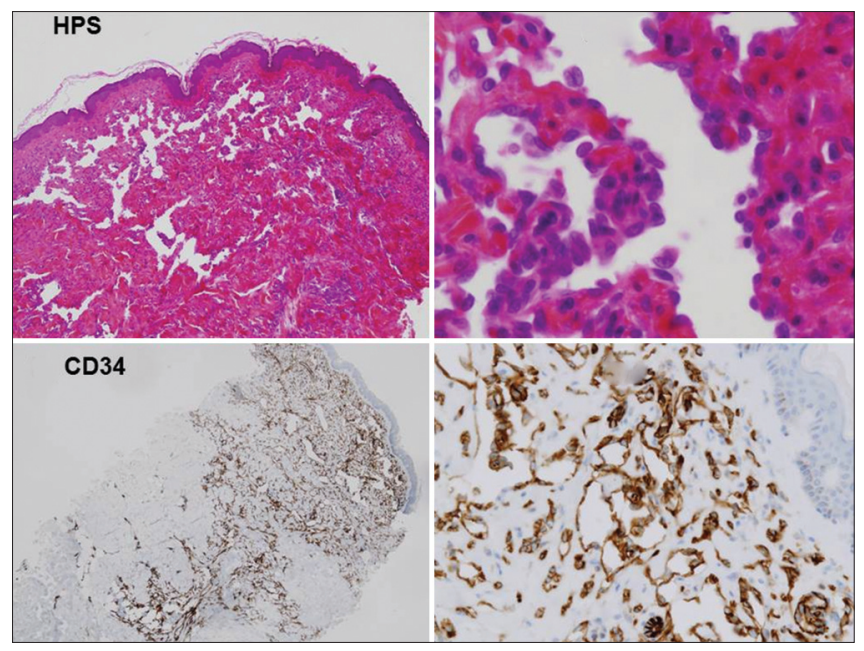

Figure 2: Histopathological lesions (a) Nodular Proliferation of fusiform cells delineating the vascular slots under an epidermal coating without atypia, after staining with HPS (Hematoxylin Phloxine Safran), and $4 \times$ magnification. (b) Details at the highest magnification (10X) of image " a ", showing the slots bordered by atypical endothelial cells (c) Intensive and diffused immuno-marking of sarcomatous proliferation, with anti-CD34 antibody, 4X. (d) Details at the highest (10X) magnification of image " $c$ ", showing an intensive marking of the membrane in tumor cells.

from a pathologist with expertise in sarcoma, were required in three of the four cases. Moreover, reviewing the initial biopsy by experts in dermatopathology allowed the diagnosis of RAAS in three of the fours cases. This strongly supports the need for systematic reviewing of any vascular lesions in patients previously treated with radiation therapy for breast cancer.

Increased risk of developing sarcoma after radiation treatment for cancer has been known for decades [8]. The interval between the treatment of the primary cancer and diagnosis of AS is usually long: 60 months in a metanalysis of 222 cases [9]. Due to the long latency period between radiation and the occurrence of AS, and due to the slow progressive development of vascular lesions and the rarity of the tumour, early recognition by both patient and physician may be difficult $[7,8]$. All the lesions were larger than $5 \mathrm{~cm}$. The interval ranged from 0 to 36 months in another series [10]. Such an interval may be detrimental to patients and emphasises the difficulties for non-specialist pathologists in differentiating benign vascular lesions from atypical and malignant lesions. D2-40 immunostaining was believed to be helpful in one series, as it was positive in 11/12 AVL and negative in 15/21 AS [11]. However, D2-40 staining was positive in all of our four cases. AVL should be considered as a slow precursor to AS or slowly progressive AS [12]. MYC amplification by Fish analysis may help to separate the two entities, as in one study it was evidenced in all the cases of RAAS and absent from those with AVL [13]. More interestingly, one study reported that immunostaining with a commercial Myc antibody was strongly related to Myc amplification in 24 of 25 cases of RAAS and staining was negative in controls (including $16 \mathrm{AVL}$ and one AS not related to radiation) [14]. More recently, Myc staining was found to be highly specific but poorly sensitive as it was negative in 12 cases of primary AS and 29 AVL, but positive in only 20 of 37 RAAS. Thus a negative Myc expression result does not rule out the diagnosis of RAAS [15].

Treatment of RAAS consists usually in mastectomy. Paclitaxel may provide clinical improvement as in one of our patients. More recently, pazopanib provided complete response in one patient and partial response in another patient and was used as maintenance therapy at low dose [16]. Complete response was also shown in one of our patient who is still in maintenance therapy.

\section{CONCLUSION}

The early diagnosis of post-radiation low grade AS may be difficult for both the clinician and the pathologist. 
The clinician should alert the pathologist in cases where the lesion is larger than $5 \mathrm{~mm}$, since AVL are often small lesions [17], and should ask for a second pathologist's opinion with expertise in sarcoma in every suspicious case.

\section{Consent}

The examination of the patient was conducted according to the Declaration of Helsinki principles.

\section{REFERENCES}

1. Ducimetière F, Lurkin A, Ranche 're-Vince D, Decouvelaere AV, Péoc'h M, Istier L, et al. Incidence of sarcoma histotypes and molecular subtypes in a prospective epidemiological study with central pathology review and molecular testing. PLoS ONE. 2011;6:e20294.

2. Schmitz-Rixen T, Horsch S, Arnold G, Peters PE. Angiosarcoma in primary lymphedema of the lower extremity--Stewart-Treves syndrome. Lymphology. 1984;17:50-3.

3. Lindet C, Neuville A, Penel N, Lae M, Michels JJ, Trassard M, et al. Localised angiosarcomas: the identification of prognostic factors and analysis of treatment impact. A retrospective analysis from the French Sarcoma Group (GSF/GETO). Eur J Cancer. 2013;49:36976.

4. Virtanen A, Pukkala E, Auvinen A. Angiosarcoma after radiotherapy: a cohort study of 332,163 Finnish cancer patients. Br J Cancer. 2007;97:115-7.

5. Brenn T, Fletcher CD. Radiation-associated cutaneous atypical vascular lesions and angiosarcoma: clinicopathologic analysis of 42 cases. Am J Surg Pathol. 2005;29:983-96.

6. Gengler C, Coindre JM, Leroux A, Trassard M, Ranchère-Vince D, Valo I, et al. Vascular proliferations of the skin after radiation therapy for breast cancer: clinicopathologic analysis of a series in favor of a benign process: a study from the French Sarcoma Group. Cancer. 2007;109:1584-98.

7. Kim PS, Neff AG, Mutasim DF, Spicknall KE. Multiple lymphatictype, atypical vascular lesions of the breast following radiation therapy. Int J Dermatol. 2013;52:195-7.
8. Fraga-Guedes C, Gobbi H, Mastropasqua MG, Rocha RM, Botteri E, Toesca A, et al. Clinicopathological and immunohistochemical study of 30 cases of post-radiation atypical vascular lesion of the breast. Breast Cancer Res Treat. 2014;146:347-54.

9. Cahan WG, Woodard HW, Higinbotham NL, Stewart FW, Coley BL. Sarcoma arising in irradiated bone: report of 11 cases. Cancer. 1948;1:3-29.

10. Depla AL, Scharloo-Karels CH, de Jong MA, Oldenborg S, Kolff MW, Oei SB, et al. Treatment and prognostic factors of radiation-associated angiosarcoma (RAAS) after primary breast cancer: a systematic review. Eur J Cancer. 2014;50:1779-88.

11. Singla S, Papavasiliou P, Powers B, Gaughan J, von Mehren M, Watson JC, et al. Challenges in the treatment of angiosarcoma: a single institution experience. Am J Surg. 2014;208:254-9.

12. Mattoch IW, Robbins JB, Kempson RL, Kohler S. Post-radiotherapy vascular proliferations in mammary skin: a clinicopathologic study of 11 cases. J Am Acad Dermatol. 2007;57:126-33.

13. Guo T, Zhang L, Chang NE, Singer S, Maki RG, Antonescu CR. Consistent MYC and FLT4 gene amplification in radiation-induced angiosarcoma but not in other radiation-associated atypical vascular lesions. Genes Chromosomes Cancer. 2011;50:25-33.

14. Mentzel T, Schildhaus HU, Palmedo G, Büttner R, Kutzner H. Postradiation cutaneous angiosarcoma after treatment of breast carcinoma is characterized by MYC amplification in contrast to atypical vascular lesions after radiotherapy and control cases: clinicopathological, immunohistochemical and molecular analysis of 66 cases. Mod Pathol. 2012;25:75-85.

15. Fraga-Guedes C, André S, Mastropasqua MG, Botteri E, Toesca A, Rocha RM, et al. Angiosarcoma and atypical vascular lesions of the breast: diagnostic and prognostic role of MYC gene amplification and protein expression. Breast Cancer Res Treat. 2015;151:131-40.

16. Miura H, Shirai H. Low-dose administration of oral pazopanib for the treatment of recurrent angiosarcoma. Clin Exp Dermatol. 2015;40:575-7.

17. Lucas DR. Angiosarcoma, radiation-associated angiosarcoma, and atypical vascular lesion. Arch Pathol Lab Med. 2009;133:1804-9.

Copyright by Nina Korsaga/Somé, et al. This is an open-access article distributed under the terms of the Creative Commons Attribution License,

which permits unrestricted use, distribution, and reproduction in any medium, provided the original author and source are credited.

Source of Support: Nil, Conflict of Interest: None declared. 